\title{
Testosterone regulation of sex steroid-related mRNAs and dopamine-related mRNAs in adolescent male rat substantia nigra
}

Tertia D Purves-Tyson 1,2,3, David J Handelsmann ${ }^{4}$, Kay L Double ${ }^{2,3}$, Samantha J Owens 1,2,3, Sonia Bustamante ${ }^{5}$ and Cynthia Shannon Weickert ${ }^{1,2,6^{*}}$

\begin{abstract}
Background: Increased risk of schizophrenia in adolescent males indicates that a link between the development of dopamine-related psychopathology and testosterone-driven brain changes may exist. However, contradictions as to whether testosterone increases or decreases dopamine neurotransmission are found and most studies address this in adult animals. Testosterone-dependent actions in neurons are direct via activation of androgen receptors (AR) or indirect by conversion to $17 \beta$-estradiol and activation of estrogen receptors (ER). How midbrain dopamine neurons respond to sex steroids depends on the presence of sex steroid receptor(s) and the level of steroid conversion enzymes (aromatase and 5a-reductase). We investigated whether gonadectomy and sex steroid replacement could influence dopamine levels by changing tyrosine hydroxylase (TH) protein and mRNA and/or dopamine breakdown enzyme mRNA levels [catechol-O-methyl transferase (COMT) and monoamine oxygenase (MAO) A and B] in the adolescent male rat substantia nigra. We hypothesized that adolescent testosterone would regulate sex steroid signaling through regulation of ER and AR MRNAs and through modulation of aromatase and 5a-reductase mRNA levels.

Results: We find ERa and AR in midbrain dopamine neurons in adolescent male rats, indicating that dopamine neurons are poised to respond to circulating sex steroids. We report that androgens ( $T$ and $D H T$ ) increase $T H$ protein and increase COMT, MAOA and MAOB mRNAs in the adolescent male rat substantia nigra. We report that all three sex steroids increase AR mRNA. Differential action on ER pathways, with ERa mRNA down-regulation and ER $\beta$ mRNA up-regulation by testosterone was found. 5 a reductase-1 mRNA was increased by AR activation, and aromatase mRNA was decreased by gonadectomy.
\end{abstract}

Conclusions: We conclude that increased testosterone at adolescence can shift the balance of sex steroid signaling to favor androgenic responses through promoting conversion of T to DHT and increasing AR mRNA. Further, testosterone may increase local dopamine synthesis and metabolism, thereby changing dopamine regulation within the substantia nigra. We show that testosterone action through both AR and ERs modulates synthesis of sex steroid receptor by altering AR and ER mRNA levels in normal adolescent male substantia nigra. Increased sex steroids in the brain at adolescence may alter substantia nigra dopamine pathways, increasing vulnerability for the development of psychopathology.

Keywords: Sex steroids, Midbrain, Estrogen receptor, Androgen receptor, Gene expression, Adolescence, Schizophrenia

\footnotetext{
* Correspondence: c.weickert@neura.edu.au

${ }^{1}$ Schizophrenia Research Institute, Sydney 2021, Australia

${ }^{2}$ Neuroscience Research Australia, Sydney 2031, Australia

Full list of author information is available at the end of the article
} 


\section{Background}

Androgens and estrogens produced by the gonads influence brain function including cognitive, motor and motivational behaviors and neurotransmitter release in midbrain dopamine circuits. Schizophrenia, characterized by hallucinations and delusions resulting from hyperactivity of the subcortical dopaminergic system (especially dorsal caudate) [1,2], affects males more severely than females [3] with the highest rate of onset seen in adolescent males [4]. Male adolescence involves a rapid increase in testosterone production leading to increased blood testosterone levels [5]. The increased risk of schizophrenia in male adolescents suggests that testosterone may directly induce transcriptional and maturational changes in midbrain dopamine neurons. However, molecular evidence supporting that sex steroids can change gene expression during the adolescent maturation of midbrain dopamine neurons does not currently exist.

Sex steroids activate ligand-dependent nuclear receptors. Testosterone initiates changes in gene expression via direct activation of androgen receptors (AR) or can interact with estrogen receptors after aromatization. Testosterone can be converted to the non-aromatisable androgen, dihydrotestosterone (DHT) by $5 \alpha$-reductase enzymes $(5 \alpha R)$ [6]. DHT is a pure androgen with greater potency at AR than testosterone and can initiate gene expression only via AR. Testosterone is also converted to estradiol by the cytochrome p450 enzyme, aromatase (Cyp19A1), to activate nuclear estrogen receptors, ER $\alpha$ and ER $\beta$. All three sex steroid receptors (ER $\alpha, E R \beta$ and AR) exist in adult rodent midbrain [7-11]. Two $5 \alpha \mathrm{R}$ isozymes, $5 \alpha \mathrm{R}-1$ and $5 \alpha \mathrm{R}-2$, are expressed in rodent and human brain during adulthood [12] and aromatase is expressed in the midbrain [13]. Androgens differentially control $5 \alpha R$ mRNA levels in the rat prefrontal cortex [14] and high levels of $5 \alpha R$ activity have been detected in rat midbrain homogenates [15]. However, it is unknown whether testosterone can regulate the enzymes involved in steroid conversion in the adolescent male substantia nigra. We hypothesized that testosterone may change aromatase and $5 \alpha \mathrm{R}$ mRNAs to alter sex steroid signaling over the period of adolescence in male rat substantia nigra.

Studies in rodents disagree as to how sex steroids modulate midbrain dopamine circuits. Some studies in adult male rats suggest that dopamine neurons are inhibited by circulating testosterone, as castration caused increased striatal dopamine release, increased locomotion and augmented the behavioral response to dopaminepotentiating drugs of abuse [16-18]. Other studies suggest the opposite, where exogenous testosterone can increase striatal dopamine levels and dopamine turnover in adult male rats $[19,20]$. Anatomically, testosterone can increase dopaminergic neuron axon density in targets [7], but may also lead to a decreased number of dopamine neurons in the midbrain [21]. Most studies have been carried out in adult rodents, but studies focusing on the adolescent period of brain development are imperative to understand the involvement of sex steroids in psychopathologies that emerge (or worsen) during adolescence.

In our study, we investigated whether gonadectomy and exogenous androgens or estradiol are able to influence dopamine neurons by changing tyrosine hydroxylase $(\mathrm{TH})$ levels, the rate limiting enzyme in the production of dopamine and/or by changing the levels of mRNA encoding for enzymes involved in dopamine metabolism such as catechol-O-methyl transferase (COMT) and monoamine oxygenase (MAO) A and $\mathrm{B}$ in the substantia nigra ( $\mathrm{SN}$ ) of adolescent male rats. We also tested the extent to which sex steroid receptor mRNA expression changes in response to testosterone and estradiol in male adolescence in the substantia nigra.

\section{Methods}

\section{Animal experiments}

All animal experiments were approved by the Animal Care and Ethics Committee of the University of New South Wales in accordance with the National Health and Medical Research Council of Australia's Code of Practice for the Care and Use of Animals for Experimental Purposes, which also conforms to standard international guidelines. Male Sprague-Dawley rats were used for all experiments (Animal Resource Centre, Perth, WA, Australia). Rats were group housed (3-4/cage) in 12/12 hr light/dark phases with constant humidity and temperature and free access to water and standard rat chow.

\section{Gonadectomy and sex steroid replacement}

Adolescent male rats were gonadectomised at 45 days of age, prior to the adolescent testosterone increase, and given continuous replacement testosterone (T), dihydrotestosterone (DHT) or 17 $\beta$-estradiol (estradiol, E) by subdermal silastic implant [22-24] for two weeks. By this age, intact animals have experienced the increase in testosterone associated with adolescence. There were five groups ( 15 rats per group): intact (Intact), gonadectomy alone (Gdx); gonadectomy plus testosterone $(\mathrm{Gdx}+\mathrm{T})$; gonadectomy plus DHT $(\mathrm{Gdx}+\mathrm{DHT})$, gonadectomy plus estradiol $(\mathrm{Gdx}+\mathrm{E})$. Male rats (45 days old) were anaesthetized with an intraperitoneal (i.p.) injection of ketamine hydrochloride $(60 \mathrm{mg} / \mathrm{kg})$ and xylazine hydrochloride (10 mg/kg) (Provet, Castle Hill, Australia). The intact animals underwent sham abdominal surgery but gonads were left in place. Silastic implants were placed under the skin between the shoulder blades at time of gonadectomy. Gdx and Intact groups were given empty implants. Implants were $1 \mathrm{~cm}$ long, internal diameter $1.47 \mathrm{~mm}$, outer diameter $1.95 \mathrm{~mm}$ (ends sealed with silastic adhesive). These 
implants have been characterized in previous studies and achieve supraphysiological, steady-state hormone levels and maintain seminal vesicle weights equal to that in untreated animals $[23,25]$. Seminal vesicles depend on androgen action for normal development and maintenance of structural and functional integrity [26]. Weight of seminal vesicles at the end of experiment served as an index of the restoration of androgen action by the implants as previously reported [25].

At 60 days of age rats were anaesthetized with $60 \mathrm{mg} / \mathrm{kg}$ sodium pentobarbital (Euthal, Delvet, Seven Hills, Australia). Brain was removed from the skull and a tissue block containing the midbrain was dissected following the Rat Brain Atlas as a guide [27]. The block was trimmed transversely at the cerebral aqueduct and two lateral segments of midbrain on either side of the ventral tegmental area (VTA) containing the SN were collected. Trunk blood was collected on day of euthanasia in $0.8 \mathrm{ml}$ serum gel tubes ( $Z$ serum sep MiniCollect tube, Greiner Bio One, Wemmel, Belgium) and serum collected by centrifugation. Left and right hemisphere midbrain segments including SN were randomly assigned for either protein or RNA extraction.

\section{Immunohistochemistry}

For immunohistochemical studies five normal intact male rats (50-53 days old) were deeply anaesthetized with pentobarbital (Euthal) followed by transcardial perfusion with $4 \%$ paraformaldehyde (PFA, $\mathrm{pH}$ 7.2). Midbrain was dissected in the coronal plane and post-fixed (4\% PFA) overnight, washed with phosphate buffered saline (PBS) and cryoprotected in 30\% sucrose/PBS.

Midbrain sections $(40 \mu \mathrm{m})$ were collected in PBS and sections from each brain between Bregma -5.52 and $-5.64 \mathrm{~mm}$ was incubated for $1 \mathrm{~h}$ with $10 \%$ horse serum (Sigma) and 0.1\% Triton X-100 (Sigma) in PBS. This was followed by incubation with primary antibodies overnight at $4^{\circ} \mathrm{C}$, washes and incubation with fluorescenceconjugated secondary antibodies for $2 \mathrm{~h}$ at room temperature. The antisera used were: $\mathrm{TH}$ (host species mouse, 1:500; MAB318, Millipore, Temecula, CA, USA) or TH (host species rabbit, 1:500; AB152, Millipore), ER $\alpha$ (host species mouse, 1:50; 6 F-11, Nova Castra, Leica-Microsystems, Wetzlar, Germany) and AR (host species rabbit, 1:200, PA1-110, Thermo Scientific, Australia, Scoresby, Victoria). ER $\beta$ immunohistochemistry was not performed as there are currently no well-validated commercial ER $\beta$ antibodies available. Primary antibody binding was visualized with fluorophore-conjugated speciesspecific secondary antibodies (donkey-anti-mouse-Alexa Fluor488 and 594, donkey-anti-rabbit-Alexa Fluor488 and 594, all 1:500, Life Technologies, Carlsbad, CA, USA). Sections incubated with only secondary antibody or with each primary antibody with the alternate (incorrect) secondary antibody confirmed that no fluorescent signal was due to non-specific or cross-over binding. Nuclei were visualized by incubation with $1 \mu \mathrm{g} / \mathrm{ml}$ DAPI (Sigma). Sections were mounted with glycerol/PBS (Citifluor AF1, London, UK). Sections were viewed under a Nikon Eclipse 80i fluorescence microscope (Nikon) with a CX9000 digital camera attached (MBF Biosciences, Williston, VT, USA). SN and VTA were demarcated under low power (4x) using StereoInvestigator (v8.27, MBF Biosciences) and referring to a Rat Brain Atlas [27]. Under higher power (20x) using StereoInvestigator, TH positive cells (100-200) were identified within the SN pars compacta, they were then assessed for receptor immunoreactivity and percentage of $\mathrm{TH}$ positive neurons expressing either receptor was determined. Images were also collected on a Nikon C1 laser scanning confocal unit (Nikon D-Eclipse C1, Nikon Australia) attached to a fluorescence microscope (Nikon Eclipse 90i). Images were acquired digitally and processed using the software EZ-C1 (v 3.5) for Nikon C1 confocal microscopes (Nikon Australia).

\section{Immunoblotting}

The substantia nigra blocks were homogenized $[0.1 \mathrm{M}$ Tris, $\mathrm{pH}$ 7.5, 50\% glycerol, proteinase inhibitor cocktail (Sigma Cat\# P8340) and aprotinin $(0.015 \mathrm{mM}$, Sigma, St Louis, MO, USA)] using a handheld electric homogenizer (Polytron, Kinematica, Lucerne, Switzerland). Protein concentration was determined using the Bradford protein assay (Sigma). An aliquot of each sample was combined and used as a standard and run in duplicate on each gel to allow standardization between blots (internal control). Standard curves with between 0.5 and $20 \mu \mathrm{g}$ SN protein were run and $\mathrm{TH}$ expression was determined to be within a linear range using $3 \mu \mathrm{g}$ protein. SDS-PAGE (10\% acrylamide) was performed on $3 \mu \mathrm{g}$ of protein per sample. Proteins were transferred to nitrocellulose $(45 \mu \mathrm{m}$, Biorad, CA, USA). Primary antibodies were anti-TH (host species mouse, 1:5000; Chemicon) and anti- $\beta$-actin (host species rabbit, 1:5000; MAB1501, Millipore). Secondary antibodies were goat anti-mouse or anti-rabbit horseradish peroxidase (HRP) conjugated (1:4000, Millipore). Immunoreactive bands were detected using the LumiGlo detection kit (LumiGlo Reagent; Cell Signaling, Danvers, MA, USA) on hyperfilm (Amersham, GE Healthcare, Uppsala, Sweden). The immunoblots were scanned and band densities converted to numerical values using ImageJ software (Image 1.43u, National Institutes of Health, USA). Relative intensity of TH bands were normalized to relative intensity of $\beta$-actin bands.

\section{RNA Extraction and cDNA Synthesis}

Total RNA was extracted from substantia nigra samples in 800-1000 $\mu \mathrm{l}$ TRIzol reagent (Life Technologies Inc., Grand Island, NY, USA) with a handheld electric homogenizor 
(Polytron) as recommended by the manufacturer. RNA was quantified using a ND-1000 Spectrophotometer (Nanodrop Technologies, Wilmington, USA). RNA integrity (RIN) was assessed with high resolution capillary electrophoresis (Agilent Bioanalyzer 2100, Agilent Technologies, Palo Alto, CA, USA). Two separate aliquots of $3 \mu \mathrm{g}$ RNA from each sample were reverse transcribed to cDNA with SuperScript III First-Strand Synthesis Supermix and random hexamers, according to the manufacturer's protocol (Life Sciences). A parallel reaction was performed without reverse transcriptase as a negative control. The 2 aliquots of cDNA from each sample were pooled and diluted for RT-PCR.

\section{Quantitative Real-Time PCR (qPCR)}

Messenger RNA (mRNA) levels of genes of interest were measured by TaqMan Gene Expression Assays (Applied Biosystems, Foster City, CA, USA) using an ABI Prism 7900HT Fast Real-Time PCR System and a 384-well format. Expression of three housekeeping genes, betaglucuronidase (GusB), $18 \mathrm{~S}$ ribosomal RNA (18 S rRNA) and glyceraldehyde 3-phosphate dehydrogenase (GAPDH), was used to calculate the normalizing control for gene expression (termed geometric mean), and were selected on the basis that they were unchanged by the treatment. The Taqman probes used were: GusB (Rn00566655); 18 s rRNA (Hs99999901); GAPDH (Rn01775763). The geometric mean of the three housekeeping genes was calculated as described previously [28]. There were no group differences when the geomean of the three housekeepers was compared $(\mathrm{F}=1.67, \mathrm{df}=4, p=0.168)$. Genes of interest were targeted by the following Taqman probes (Applied Biosystems): TH (Rn00562500), COMT (Rn00561037), MAOA (Rn01430950), MAOB (Rn00566203), ER $\alpha$ (Rn01640372), ER $\beta$ (Rn00562610), AR (Rn00560747)

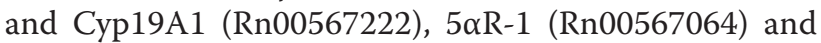
$5 \alpha$ R-2 (Rn00575595, 5 $\alpha$ R-2 mRNA levels in midbrain were too low to be accurately quantitated). Samples were run alongside a seven point standard curve using serial dilutions of cDNA derived from midbrain RNA pooled from a subset of 25 rats (taken from all treatment groups). No template controls were included which produced no signal for any mRNA examined. Measurements were performed in triplicate. PCR cycling conditions were: $50^{\circ} \mathrm{C}$ for 2 minutes, $95^{\circ} \mathrm{C}$ for 10 minutes, 50 cycles of $95^{\circ} \mathrm{C}$ for 15 seconds and $60^{\circ} \mathrm{C}$ for 1 minute. PCR data were captured with Sequence Detector Software (SDS version 2.4, Applied Biosystems). SDS software plotted real-time fluorescence intensity and the threshold was set within the linear phase of the amplification profiles.

\section{Sex steroid measurements}

Testosterone $(\mathrm{T})$, dihydrotestosterone (DHT) and $17 \beta$ estradiol (estradiol, E) were quantified in extracts of serum using a stable isotope dilution liquid chromatographytandem mass spectroscopy (LC-MS/MS) method as described [29] and adapted for rodents [30]. The limit of quantitation for this method is $0.025 \mathrm{ng} / \mathrm{ml} \mathrm{T}, 0.1 \mathrm{ng} / \mathrm{ml}$ DHT and $5 \mathrm{pg} / \mathrm{ml} \mathrm{E.} \mathrm{T} \mathrm{and} \mathrm{DHT} \mathrm{were} \mathrm{also} \mathrm{measured} \mathrm{in}$ serum extracts using a gas chromatography MS (GC-MS) method adapted from Horning et al., [31] (data presented in additional material).

\section{Statistics}

Unless otherwise stated statistical analyses were conducted using SPSS software (IBM SPSS Statistics, version 19) and $p<0.05$ was considered statistically significant. Seminal vesicle and body weight (g) data are shown as mean \pm standard error of the mean (SEM). Immunoblotting data are presented as percent change of relative intensity compared to the Gdx group \pm SEM. Immunoblotting data were normalized to $\beta$-actin expression and population outliers removed by performing Grubbs test for outliers (GraphPad Software). Data was then analyzed by one-way ANOVA followed by Fisher's least significant differences (LSD), post hoc.

QPCR data are presented as percent change of mRNA levels relative to the Gdx group \pm SEM. Outlier detection of the triplicates obtained from the GPCR raw data was used to exclude measurement errors [32]. qPCR raw data was normalized by the geomean of the housekeepers. Population outliers were removed by performing Grubb's test on the normalized data and data were analyzed by one-way ANOVA followed by Fisher's LSD.

\section{Results}

Confirmation of sex steroid replacement by organ weight There were no significant differences in overall body growth between any of the five experimental groups (the mean - of all 5 groups - increase in body weight over the course of study was $44.0 \pm 2.0 \%$ ) (Figure $1 \mathrm{~A}$ ). There were no significant group differences in brain weight (results not shown). There was a significant effect of treatment group when examining seminal vesicle weights $(\mathrm{F}=149.2$, $\mathrm{df}=4, p<0.0001)$. Gdx reduced seminal vesicles to $9.0 \%$ weight of Intact group (Figure 1B). Seminal vesicles were maintained at $94.2 \%$ of intact weights by replacement testosterone and at $44 \%$ of intact weights by replacement DHT. Estradiol replacement had no effect on seminal vesicle weights such that the $G d x+E$ group was not significantly different to the Gdx group.

\section{Confirmation of sex steroid replacement by blood levels}

DHT and T were measured by LC-MS/MS and GC-MS methods. Estradiol was detectable only by LC-MS/MS. Comparisons of GC-MS and LC-MS/MS androgen measurements in sera samples are included in additional material (see Additional Material File 1). As LC-MS/MS proved 


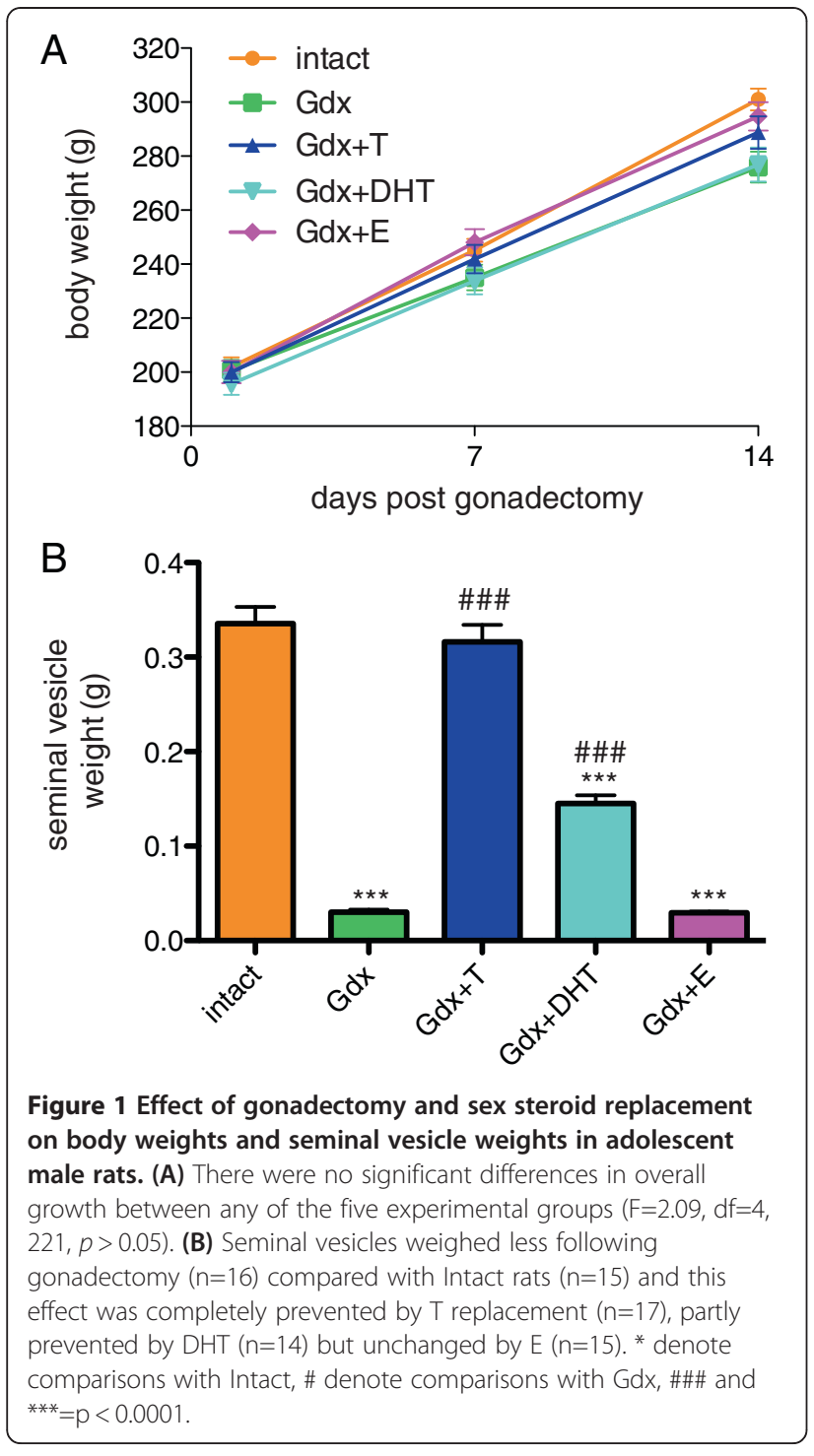

to require less serum $(200 \mu \mathrm{l})$ and was able to detect circulating estradiol we report these measurements. Average circulating serum testosterone was $0.03 \pm 0.001 \mathrm{ng} / \mathrm{ml}$ in the Gdx group $(\mathrm{n}=9), 2.8 \pm 0.6 \mathrm{ng} / \mathrm{ml}(\mathrm{n}=12)$ in the Intact group and $23.1 \pm 12.0 \mathrm{ng} / \mathrm{ml}$ in the $\mathrm{Gdx}+\mathrm{T}$ group $(\mathrm{n}=14)$. Average circulating serum DHT was not detectable in the Gdx group $(\mathrm{n}=8), 0.2 \pm 0.03 \mathrm{ng} / \mathrm{ml}$ in the Intact group ( $\mathrm{n}=7$ ), and $21.42 \pm 10.6 \mathrm{ng} / \mathrm{ml}$ in the $\mathrm{Gdx}+\mathrm{DHT}$ group $(\mathrm{n}=12)$. Circulating serum estradiol was $7.3 \pm$ $0.15 \mathrm{pg} / \mathrm{ml}$ (duplicate measure of 8 pooled samples) in the Intact group and $17.0 \pm 6.7 \mathrm{pg} / \mathrm{ml}$ in the $\mathrm{Gdx}+\mathrm{E}$ group $(n=8)$.

\section{Anatomical co-localization of AR and ER and TH in substantia nigra dopamine neurons}

Co-localization of $\mathrm{TH}$ and sex steroid receptors was indicated by AR immunoreactivity in $~ 65.5 \pm 3.5 \%$ of $\mathrm{TH}$ positive $(\mathrm{TH}+)$ neurons and $\mathrm{ER} \alpha$-immunoreactivity in $\sim 39.9 \pm 4.4 \%$ of $\mathrm{TH}+$ neurons in the normal intact male adolescent substantia nigra (50-53 days old, $\mathrm{n}=5$ ) (Figure 2), indicating that many dopamine neurons in the substantia nigra could respond directly to sex steroids. Sex steroid receptor immunoreactivity was also present in $\mathrm{TH}$ negative cells.

\section{Regulation of substantia nigra TH protein by sex steroids}

$\mathrm{TH}$ protein was detected at the expected molecular weight of $60 \mathrm{kDa}$ and $\beta$-actin at $43 \mathrm{kDa}$ (Figure 3A). There was a significant effect of treatment group on $\mathrm{TH} / \beta$-actin protein levels in the substantia nigra in adolescent male rats $(\mathrm{F}=4.43, \mathrm{df}=4, p=0.0043)$. $\mathrm{TH}$ protein in the substantia nigra was increased $70 \%$ in the $\mathrm{Gdx}+\mathrm{T}$ group relative to the Gdx group and $106 \%$ relative to the Intact group (Figure 3B). There were no significant differences in $\mathrm{TH}$ protein levels between Intact, $\mathrm{Gdx}$, $\mathrm{Gdx}+\mathrm{DHT}$ or $\mathrm{Gdx}+\mathrm{E}$ groups.

\section{Regulation of substantia nigra TH mRNA by sex steroids}

There was no overall effect of treatment group on $\mathrm{TH}$ mRNA ( $\mathrm{F}=1.97, \mathrm{df}=4, p=0.109)$ in the $\mathrm{SN}$ of adolescent male rats. Fisher's LSD post hocs were run as we hypothesized, a priori, that there would be an increase in TH mRNA with testosterone. There was a trend for TH mRNA to be increased in the $\mathrm{Gdx}+\mathrm{T}$ group when compared to the Intact (13.6\%) and Gdx (15.4\%) groups (intact vs. $\mathrm{Gdx}+\mathrm{T} ; p=0.073 ; \mathrm{Gdx}$ vs. $\mathrm{Gdx}+\mathrm{DHT}, p=0.092$ ) (Figure 3C).

\section{Modulation of dopamine metabolite enzyme mRNAs by sex steroids}

There was a significant effect of treatment group on COMT $(\mathrm{F}=6.65, \mathrm{df}=4, p<0.0001)$, MAOA $(\mathrm{F}=9.983$, $\mathrm{df}=4, p<0.0001)$ and MAOB $(\mathrm{F}=5.35, \mathrm{df}=4, p<0.001)$ mRNA expression in the adolescent male rat substantia nigra. All three breakdown enzyme mRNAs were significantly increased in the $\mathrm{Gdx}+\mathrm{T}$ and $\mathrm{Gdx}+\mathrm{DHT}$ groups when compared to the Intact or Gdx groups (all p's $<0.05)$. None of the breakdown enzyme mRNA expression levels were changed in the $\mathrm{Gdx}+\mathrm{E}$ group compared to the Intact or Gdx groups (Figure 4A, B, C).

\section{Modulation of androgen and estrogen receptor mRNAs by sex steroids}

We detected a significant effect of treatment group on AR mRNA expression $(\mathrm{F}=11.3, \mathrm{df}=4, p<0.0001)$ in the male SN. AR mRNA was increased by $45 \%, 32.5 \%$ and $26 \%$ in the $\mathrm{Gdx}+\mathrm{T}, \mathrm{Gdx}+\mathrm{DHT}$ and $\mathrm{Gdx}+\mathrm{E}$ groups, respectively, compared to the Gdx group and 39.8\%, 27.7\% and $21.4 \%$ in the $\mathrm{Gdx}+\mathrm{T}, \mathrm{Gdx}+\mathrm{DHT}$ and $\mathrm{Gdx}+\mathrm{E}$ groups, respectively, compared to the Intact group (Figure 5A). There was no significant difference in AR mRNA 


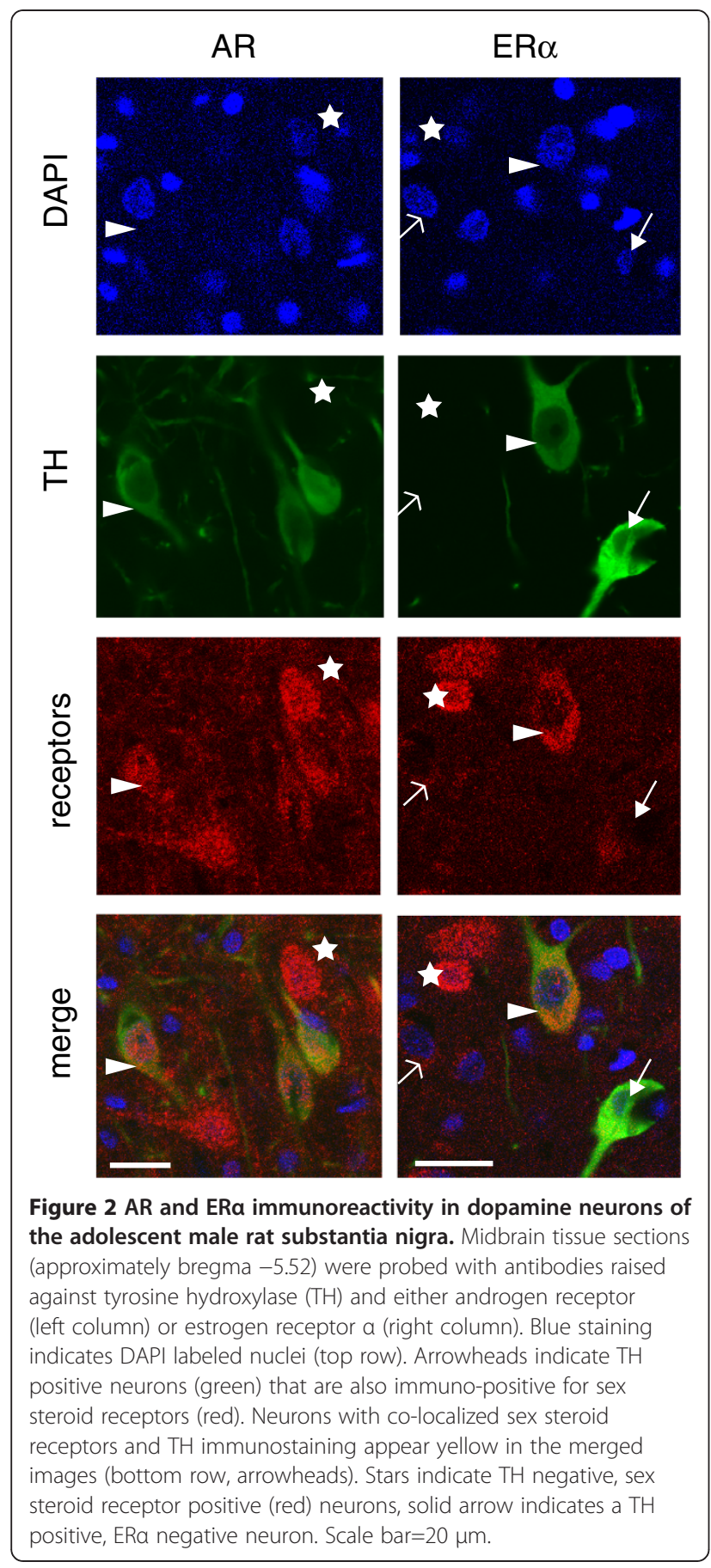

relative expression between the Intact and Gdx groups. We also found a significant effect of treatment on ER $\alpha$ mRNA expression $(\mathrm{F}=2.8, \mathrm{df}=4, p=0.032)$ in the male SN. ER $\alpha$ mRNA was significantly decreased $24.3 \%$ in the $\mathrm{Gdx}+\mathrm{DHT}$ group compared to the Intact group. There were no significant differences in ER $\alpha$ mRNA relative expression between GDX+T and GDX+E relative to the Gdx and Intact groups. The decrease in ER $\alpha$ mRNA relative expression (14.2\%) in the Gdx group compared

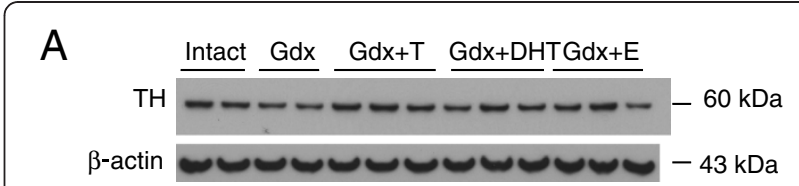

$\mathrm{B}$

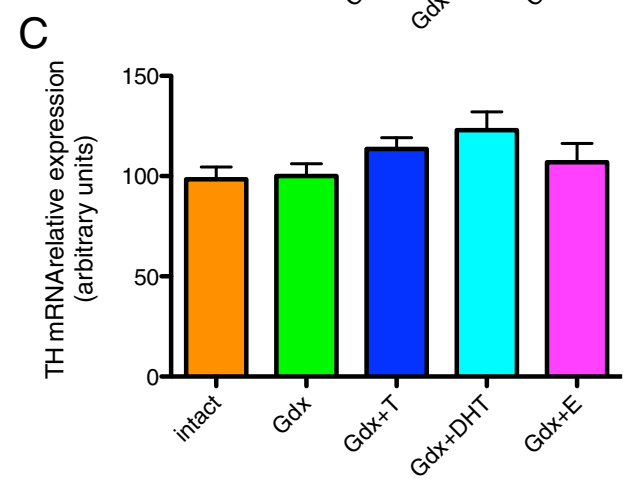

Figure 3 Effect of gonadectomy and sex steroid replacement on TH protein and mRNA in adolescent male rats.

(A) Representative immunoblots of a subset of substantia nigra samples from all five groups showing TH protein (60 kDa) and $\beta$-actin protein $(43 \mathrm{kDa})$. (B) TH protein was increased by testosterone $(n=10)$ compared to Intact $(n=10)$ and $G d x(n=10)$ groups, whereas DHT $(n=8)$ and $E(n=10)$ did not increase TH protein. $G d x+T$ was significantly different to $\mathrm{Gdx}+\mathrm{DHT}$ and $\mathrm{Gdx}+\mathrm{E}{ }^{* * *}=p<0.001$, and significantly different to $\mathrm{Gdx}$ and Intact, $p<0.05$ and $p<0.01$, respectively. (C) TH mRNA was measured using real time qPCR. Midbrain TH mRNA relative expression was not significantly different according to treatment group.

to the Intact group did not reach statistical significance (Intact vs. Gdx, $p=0.089$ ) (Figure 5B). We detected an effect of treatment group on ER $\beta$ mRNA expression in the male adolescent $\mathrm{SN}(\mathrm{F}=2.6, \mathrm{df}=4, p=0.045)$. ER $\beta$ mRNA expression was significantly increased in the $\mathrm{Gdx}+\mathrm{T}$ (27\%) and Gdx+DHT (20\%) groups (Figure 5C).

\section{Modulation of sex steroid conversion enzyme mRNAs by sex steroids}

We found a significant effect of treatment group on Cyp19A1 mRNA ( $\mathrm{F}=2.8, \mathrm{df}=4, p=0.034)$ with decreased expression (40.4\%) in the Gdx group compared to the Intact group and this was not reversed by replacement of any of the three sex steroids compared to Gdx and all replacement groups were significantly decreased compared to Intact group (Figure 6A). We also found a 

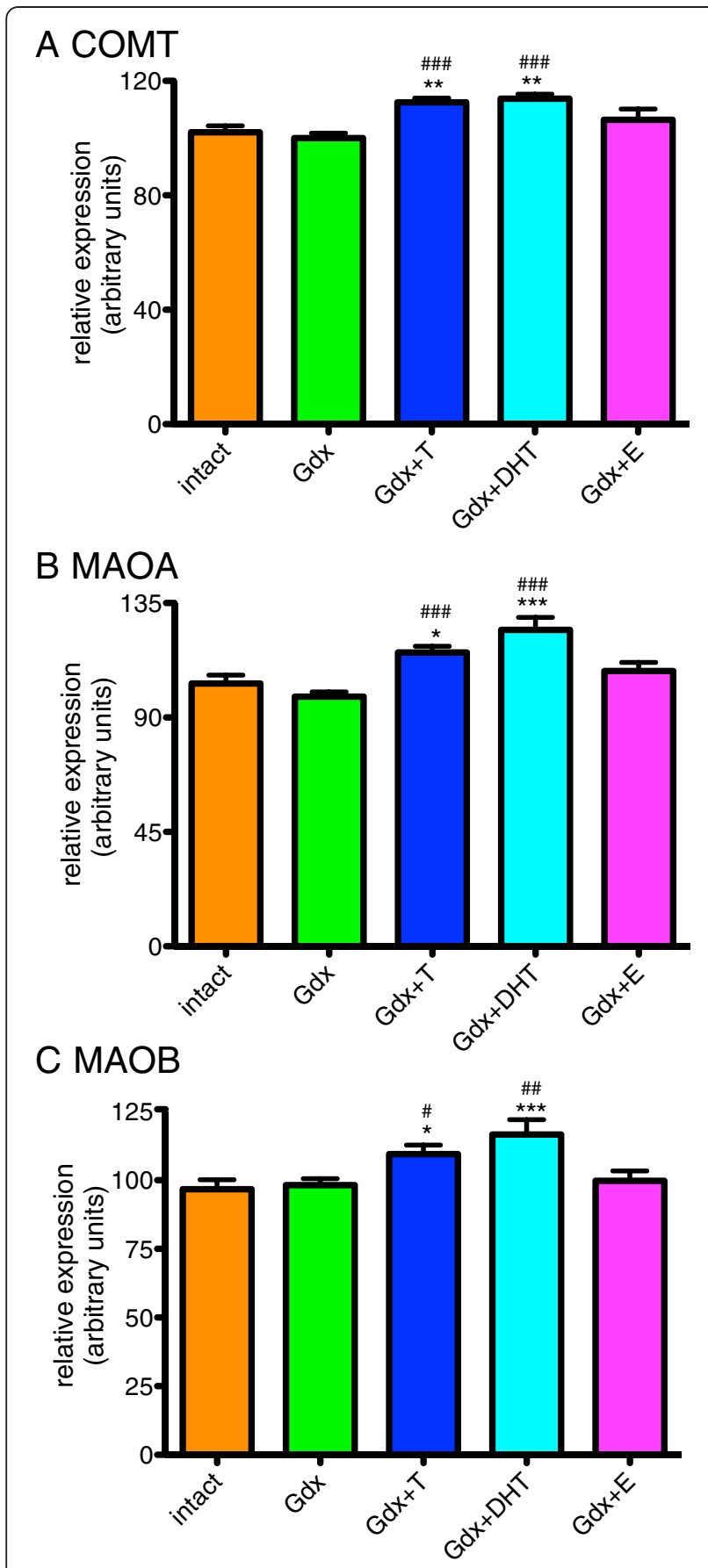

Figure 4 Effect of gonadectomy and sex steroid replacement on dopamine metabolic enzyme COMT, MAOA and МАOB mRNA in the substantia nigra of adolescent male rats. (A) COMT mRNA levels were significantly increased by $T$ and $D H T$ when compared to both Gdx and Intact groups. (B) MAOA mRNA and (C) MAOB mRNA levels were significantly increased by $T$ and $\mathrm{DHT}$ when compared to both $\mathrm{Gdx}$ and Intact groups. * denotes comparisons with the Intact group, \# denotes comparisons with the Gdx group. ${ }^{*}$ and $\#=p<0.05,{ }^{* *}$ and $\# \#=p<0.01,{ }^{* * *}$ and $\# \# \#=p<0.0001$. significant effect of treatment group on $5 \alpha \mathrm{R}-1$ mRNA expression $(\mathrm{F}=3.76, \mathrm{df}=4, p=0.009)$. Relative expression of $5 \alpha \mathrm{R}-1 \mathrm{mRNA}$ was increased by $17.4 \%$ in the Gdx+DHT group when compared to the Intact group. There was a trend for $5 \alpha \mathrm{R}-1$ mRNA expression to be increased (9.7\%) in the $\mathrm{Gdx}+\mathrm{T}$ group compared to the Intact group (intact vs. $\mathrm{Gdx}+\mathrm{T}, p=0.07)$ and $5 \alpha \mathrm{R}-1$ was unchanged by estradiol (Figure 6B).

\section{Discussion}

Sex steroids have been implicated in the modulation of neurotransmitter systems, including dopamine, albeit with conflicting reports on the direction of change [1620]. The psychotic symptoms associated with schizophrenia are thought to be driven by increased dopamine neurotransmission in subcortical brain regions [1,2], but the underlying causes of this hyperdopaminergia are unknown. The greater prevalence of schizophrenia in males, the peak of onset during adolescence, the increased symptom severity and the earlier age of onset relative to females $[3,4,33,34]$ all point toward a contribution by testosterone, which increases during male adolescence, in the etiology of schizophrenia [35,36]. However, the mechanisms by which testosterone contributes to the disorder in males are uncertain. We report that $\mathrm{TH}$ protein as well as COMT, MAOA and MAOB mRNA expression levels in the substantia nigra of adolescent male rats are sensitive to changes in testosterone via androgenic mechanisms but appear to be relatively insensitive to changes in estrogen alone over the male adolescent period.

Our results demonstrate the presence of ER $\alpha$ and AR mRNA and protein and ER $\beta$ mRNA in the substantia nigra of adolescent rat midbrain. Our data are in agreement with previous studies demonstrating ER $\alpha[11,37]$ and AR [38] in midbrain dopamine neurons (although see [38]). Studies in adult male rats indicate that ER $\beta$ is also expressed in the substantia nigra $[10,39]$ and many ER $\beta$ positive neurons are TH positive [40]. All three receptors have been identified in the substantia nigra in male rat pups up to postnatal day 30 (PN30) [11]. Our study highlights that dopamine neurons of the substantia nigra are able to respond directly to testosterone, or to testosterone converted to estradiol, during the male adolescent period.

Precisely how neurons respond to sex steroids will depend on the type, the combination and the levels of sex steroid receptor(s) and steroidogenic enzymes expressed and the nature of receptor activation via either $5 \alpha$ reduction and/or aromatization of testosterone. In our study, AR mRNA was positively regulated by all three sex steroids, implicating both androgenic and estrogenic mechanisms in the testosterone-induced up-regulation of midbrain AR gene expression. In contrast, estrogen receptor mRNAs were only changed by 


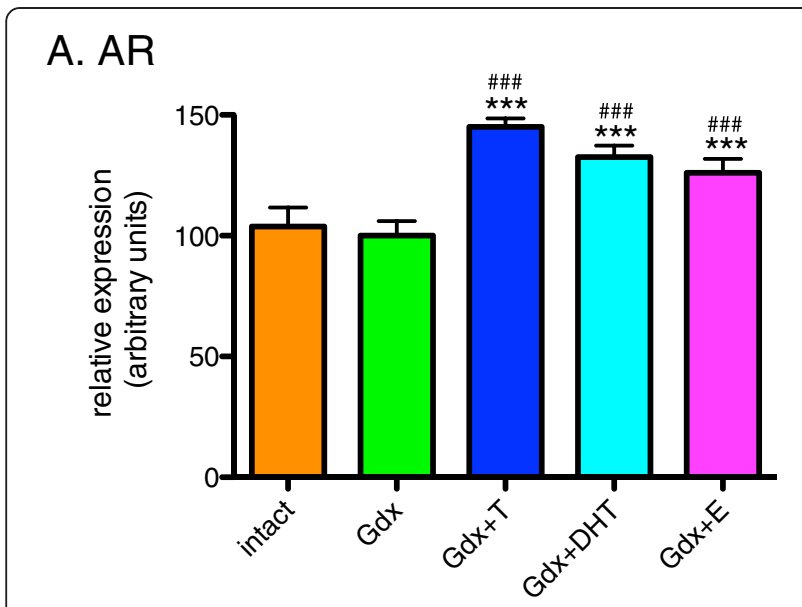

B. ER $\alpha$
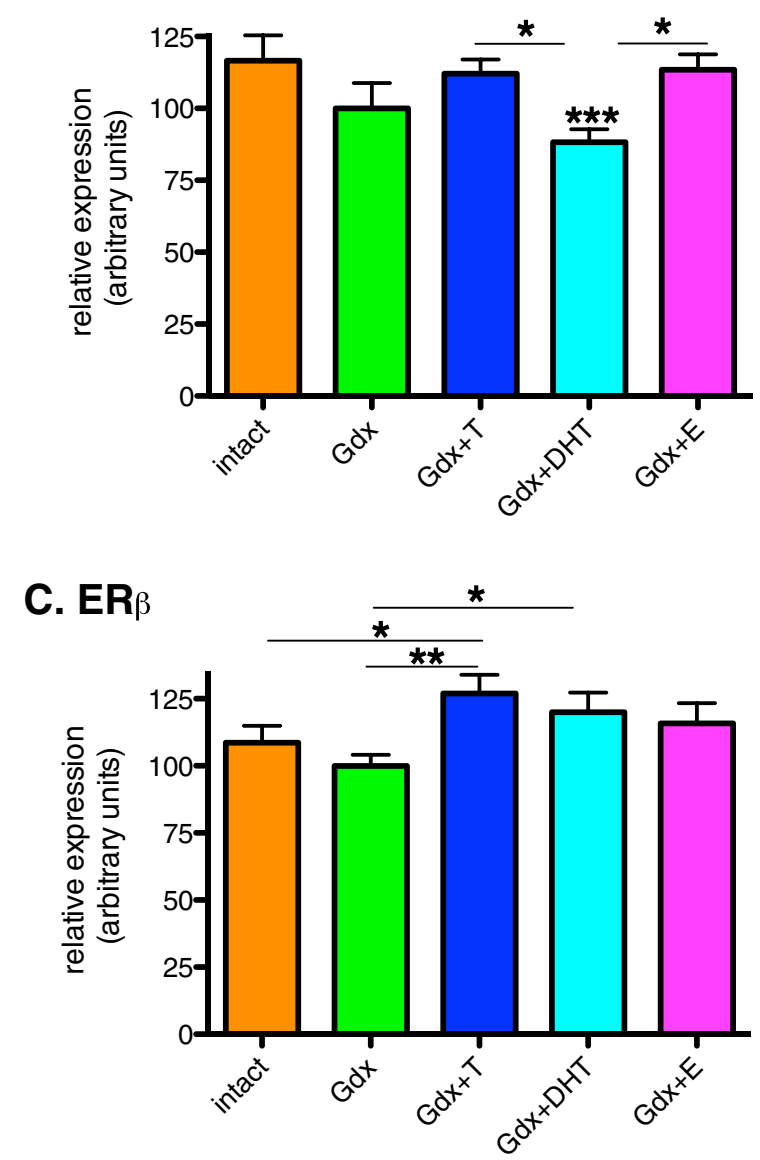

Figure 5 The effect of gonadectomy and sex steroid replacement on sex steroid receptor mRNA expression in adolescent male rat substantia nigra. (A) AR mRNA levels were increased by T, DHT and E compared to Intact (*) and Gdx (\#) groups (n=12-14/group). (B) ERa mRNA was decreased by DHT replacement compared to the Intact group. T and $\mathrm{E}$ did not change ERa mRNA levels and were significantly different to the DHT treated group. (C) ERß mRNA was increased by T (compared to Intact and Gdx groups) and by DHT (compared to Gdx only), but not by E. ${ }^{*}=p<0.05,{ }^{* *}=p<0.01,{ }^{* * *}$ and $\# \# \#=p<0.0001$. androgens and not by estrogen. We found opposite androgen regulation of ER $\alpha$ mRNA compared to ER $\beta$ mRNA where ER $\alpha$ mRNA was down-regulated by DHT and ER $\beta$ mRNA was up-regulated by testosterone and DHT. When co-expressed with $\mathrm{ER} \alpha$, via heterodimerization with $\mathrm{ER} \alpha$, ER $\beta$ can exert an inhibitory effect on ER $\alpha$-mediated gene expression and in many instances opposes the actions of ER $\alpha[41,42]$. Our results suggest that testosterone may coordinate simultaneous changes in sex-steroid receptors to increase responsiveness to testosterone through $A R$ and $E R \beta$ and reduce responsiveness through ER $\alpha$ via decreased $E R \alpha$ and increased ER $\beta$ mRNAs.

Our data suggest that, during adolescence, testosterone may modulate dopaminergic tone within the substantia nigra by increasing levels of enzymes regulating both the production and metabolism of dopamine, suggestive of a local increase in dopamine utilization and turnover within this brain region. Our data suggest that this regulation of $\mathrm{TH}$ protein and COMT, MAOA and MAOB mRNAs is not mediated via ERs, but rather through AR. However, studies in ER $\alpha$ knock out mice showed reduced levels of $\mathrm{TH}$ in male and female midbrain, indicating that significant changes in $\mathrm{TH}$ can be mediated by loss of ER $\alpha$ [43]. In the knock out mouse, the ER $\alpha$ gene is changed from early development and the developmental trajectory driven by sex steroids of these neurons may be very different to animals with normal ER $\alpha$ expression. Studies in ER $\beta$ knockout mice show morphological abnormalities including neuronal shrinkage and neuronal loss in the substantia nigra indicating ER $\beta$ is important for midbrain neuronal survival [44]. Testosterone increased ER $\beta$ mRNA in our study, implying that testosterone can potentially contribute to ER $\beta$ mediated effects such as neuron survival and maturation.

We did observe that pure AR stimulation through DHT may lead to decreased TH protein levels relative to testosterone replacement suggesting testosterone action on TH protein levels may vary, depending on if only AR (DHT) or both AR and ERs (testosterone) are stimulated. However, the apparent lack of capacity for TH protein to be increased by DHT compared to T may also be due to a dose effect if an inverted U-shaped dose response curve of TH protein to AR stimulation exists, as DHT is more potent at the AR than $\mathrm{T}$ and equivalent replacement concentrations $(\sim 21 \mathrm{ng} / \mathrm{ml})$ were achieved. This possibility would need to be tested with further studies.

Dendritic release of dopamine in the substantia nigra results in a feedback inhibition of dopamine neurons that regulates their excitability [45], increased levels of dopamine metabolic enzymes, COMT and MAOA and $\mathrm{B}$, at the cell bodies in response to increased testosterone, as we report here, suggests a mechanism that may shorten the duration of feedback inhibition via released dopamine and thus regulate dopaminergic tone. In 

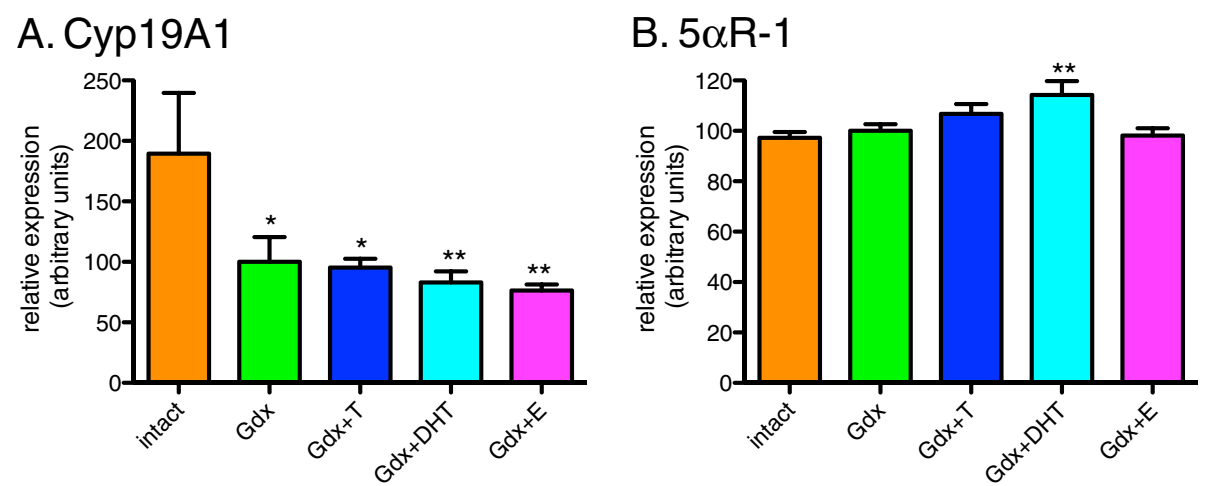

Figure 6 The effect of gonadectomy and sex steroid replacement on steroid conversion enzyme mRNA expression in adolescent male rat substantia nigra. (A). Cyp19A1 mRNA was decreased by gonadectomy and this was not prevented by T, DHT or E replacement. * denotes comparisons with Intact, ${ }^{*}=p<0.05,{ }^{* *}=p<0.01$ (B). 5aR-1 mRNA was increased by DHT compared to the Intact group but not by T or $E$ replacement. ${ }^{* *} \mathrm{p}=<0.01$.

previous studies in adult male rats, although gonadectomy had no effect, testosterone replacement increased COMT activity in both cortex and striatum [46]. Testosterone attenuated the gonadectomy-induced increase in MAOA activity in the cortex, while MAOA activity was unchanged in the striatum and MAOB activity was unchanged in either region [46]. A study in intact adult male rats treated with injections of the androgen, nandrolone, reported decreased activity of MAOA and B with a low dose in the dorsal striatum whereas a high dose increased MAOB mRNA in the substantia nigra only and MAOA and COMT mRNA levels were unchanged in all regions [47]. Our data strengthen this existing data and demonstrate that testosterone can contribute to changes in regulatory potential of dopamine neurons in the substantia nigra. Our results highlight the potential for adolescencedriven increases in circulating testosterone to augment the capacity of midbrain neurons to synthesise and break down dopamine in the normal adolescent male rat substantia nigra. We propose that in individuals with an underlying susceptibility to schizophrenia, such as a genetic variation of the COMT gene $[48,49]$, these androgendriven increases in dopamine metabolic enzyme mRNAs may contribute to dopamine dysregulation in the substantia nigra at adolescence.

Other factors that may modify brain responses to increasing testosterone at adolescence include changing levels of steroidogenic enzymes. In adolescent male rats, we report increased levels of mRNA of the enzyme that converts T to DHT, $5 \alpha \mathrm{R}-1$, due to DHT (AR) but not estradiol (ERs). Increases in local levels of $5 \alpha R$ steroidogenic enzymes may increase local levels of non-aromatisable androgens (DHT) and serve to potentiate the increase in testosterone action via AR putatively creating a positive feedback loop. Gonadectomy resulted in decreased aromatase mRNA, responsible for converting $\mathrm{T}$ to $\mathrm{E}$, in the midbrain, and this reduction was not reversed by replacement of any sex steroid. Thus, removing the male gonads appears to bias the midbrain toward more limited estradiol synthesis. Our data is in contrast to the hypothalamus, where testosterone is a major regulator of aromatase [50] suggesting significant regional differences exist. In the substantia nigra, decreased or unchanged levels of aromatase and increased levels of $5 \alpha \mathrm{R}-1$ in the midbrain could be expected to shift the balance of sex steroid signaling towards AR driven events, consistent with the AR-mediated induction of AR mRNA that we find. Inhibition of $5 \alpha \mathrm{R}$ activity has been shown to counter several psychotic-like behavioral effects induced by apomorphine treatment in rats [51]. As testosterone increases with the onset of puberty more testosterone is available for reduction to DHT by $5 \alpha \mathrm{R}-1$, which in turn would be expected to increase the level of $5 \alpha \mathrm{R}-1$ mRNA. If, as suggested, increased $5 \alpha \mathrm{R}$ (and therefore increased DHT) contributes to psychosis [52], this positive feedback loop may trigger psychosis in individuals with an underlying susceptibility towards hyperdopaminergia and schizophrenia.

Deficits in prepulse inhibition (PPI, a measure of sensorimotor gating that is regulated by dopamine) that result from an inability to appropriately integrate sensory information with a motor response, are associated with schizophrenia and degree of PPI deficit can be used as an index of schizophrenia-like behavior [53]. In contrast, we have found that PPI was attenuated during normal male adolescent development in primates [54]. Rhesus Macaques, that had undergone prepubertal gonadectomy had a robust PPI response, suggesting that the presence of adolescent testosterone may induce brain and behavioral changes which appear similar to what is found in schizophrenia (diminished PPI) and may increase manifestation of psychiatric-like symptoms. In rats, male castration did not change baseline PPI in adulthood, but serotonin receptor- 
stimulated changes in PPI differed in castrated rats compared to testosterone replaced rats [55]. Additionally, in adult male aromatase knockout mice (ArKO), which have higher levels of testosterone, baseline PPI is decreased with age when compared to controls [56]. Although PPI was not measured in our study, our results suggest that alterations in dopamine neurotransmission may contribute to the molecular basis for how changing testosterone may impact PPI during adolescence and confirm our observation of testosterone regulation of TH levels in the adolescent male monkey striatum [54].

In summary, treatment with exogenous sex steroids, be it $\mathrm{T}, \mathrm{DHT}$ or $\mathrm{E}$, shifted the adolescent male rat midbrain to a more androgen responsive state. In addition, increasing levels of circulating testosterone in male adolescence could be anticipated to increase AR mRNA, decrease ER $\alpha$ mRNA and increase ER $\beta$ mRNA. The underlying susceptibility to schizophrenia may involve the inability of the brain to respond appropriately to sex steroids [57], which is unmasked at adolescence. For example, either lower endogenous ER $\alpha$ [57] and/or increased AR signaling could be exaggerated by adolescent testosterone and thus, testosterone could shift the individual toward a dysregulated dopaminergic state. As yet, the levels of sex steroid receptors or sex steroid conversion enzymes have not been specifically measured in the midbrain of patients with schizophrenia.

\section{Conclusions}

In conclusion, the mechanism of testosterone action in the adolescent male rat substantia nigra includes regulation of $\mathrm{TH}$ levels and dopamine metabolic enzymes as well as modulation of sex steroid signaling by controlling levels of sex steroid receptor and androgen activating enzyme gene expression. Understanding how testosterone action modulates synthesis of sex steroid receptors and androgen activation in the normal adolescent male substantia nigra increases our understanding of the potential role of sex steroids in dopamine neuron activity at adolescence and how sex steroids may contribute to psychopathology involving dopamine dysregulation.

\section{Additional file}

Additional file 1: Comparison of LC-MS/MS and GC-MS measurements of circulating testosterone and DHT in rat sera. Circulating androgens were measured in sera using two mass spectroscopy methods, GC-MS and LC-MS/MS. Correlations of testosterone and DHT levels measured by the two methods were performed. Testosterone levels measured by GC-MS and LC-MS/MS correlated $(r=0.86, p<0.0001)$

\section{Abbreviations}

18 S rRNA: 18S Ribosomal Ribonucleic Acid; 5aR: 5 alpha Reductase; ANOVA: Analysis Of Variance; AR: Androgen Receptor; ArKO: Aromatase
Knockout; cDNA: Complementary Deoxyribonucleic Acid; COMT: Catechol-OMethyl Transferase; DHT: Dihydrotestosterone; E: 17ß-Estradiol; ER: Estrogen Receptor; GAPDH: Glyceraldehyde-3-Phosphate Dehydrogenase; Gdx: Gonadectomy; GusB: Beta-Glucuronidase; GUSB: Glucuronidase- $\beta$; HRP: Horse Radish Peroxidase; LC-MS/MS: Liquid Chromatography Tandem Mass Spectroscopy; MAO: Monoamine Oxidase; mRNA: Messenger Ribonucleic Acid; PBS: Phosphate Buffered Saline; PFA: Paraformaldehyde; PN: PostNatal; PPI: Prepulse Inhibition; qPCR: Quantitative real-time Polymerase Chain Reaction; RIN: Ribonucleic acid Integrity Number; RT: Room Temperature; RT-PCR: Reverse Transcriptase Polymerase Chain Reaction; SEM: Standard Error of the Mean; SN: Substantia Nigra; T: Testosterone; TH: Tyrosine Hydroxylase; VTA: Ventral Tegmental Area.

\section{Competing interests}

The authors declare that they have no competing interests.

\section{Authors' contributions}

TPT helped conceive, design, coordinate and interpret the study and carried out all the experiments, except for the LC-MS/MS analysis of sera and dopamine breakdown enzyme qPCRs, and drafted the manuscript. DJH provided the silastic implants and the LC-MS/MS analysis and gave critical comments on the manuscript. SJO completed the dopamine breakdown enzyme qPCRs. SB provided GC-MS analysis of androgens in sera and provided comments on the manuscript. KLD helped conceive and design the study and helped draft the manuscript. CSW helped conceive, design, coordinate and interpret the study and edited the manuscript. All authors have read and approved the final manuscript.

\section{Acknowledgements}

CSW and the Schizophrenia Research Laboratory are supported by the Schizophrenia Research Institute (utilising infrastructure funding from the NSW Ministry of Health and the Macquarie Group Foundation), the University of New South Wales, and Neuroscience Research Australia. This study was supported by an NH\&MRC Project Grant to CSW and KLD (\#1020981). CSW is the recipient of a NH\&MRC (Australia) Research Fellowship (\#1021970). KLD is the recipient of a NH\&MRC (Australia) Senior Research Fellowship (\#401101).

\section{Author details}

${ }^{1}$ Schizophrenia Research Institute, Sydney 2021, Australia. ${ }^{2}$ Neuroscience Research Australia, Sydney 2031, Australia. ${ }^{3}$ School of Medical Sciences, University of New South Wales, Sydney 2031, Australia. ${ }^{4}$ ANZAC Research Institute, Concord 2139, Australia. ${ }^{5}$ Bioanalytical Mass Spectroscopy Facility, University of New South Wales, Sydney 2031, Australia. ${ }^{6}$ School of Psychiatry, University of New South Wales, Sydney 2031, Australia.

Received: 9 May 2012 Accepted: 6 July 2012

Published: 6 August 2012

\section{References}

1. Kegeles LS, Abi-Dargham A, Frankle WG, Gil R, Cooper TB, Slifstein M, Hwang DR, Huang Y, Haber SN, Laruelle M: Increased synaptic dopamine function in associative regions of the striatum in schizophrenia. Arch Gen Psychiatry 2010, 67(3):231-239.

2. Howes OD, Kambeitz J, Kim E, Stahl D, Slifstein M, Abi-Dargham A, Kapur S: The nature of dopamine dysfunction in schizophrenia and what this means for treatment: meta-analysis of imaging studies. Arch Gen Psychiatry 2012. doi:10.1001/archgenpsychiatry.2012.169. Published online April 02, 2012

3. McGrath J, Saha S, Welham J, El Saadi O, MacCauley C, Chant D: A systematic review of the incidence of schizophrenia: the distribution of rates and the influence of sex, urbanicity,migrant status and methodology. BMC Med 2004, 2:13

4. Christie KA, Burke JD Jr, Regier DA, Rae DS, Boyd JH, Locke BZ: Epidemiologic evidence for early onset of mental disorders and higher risk of drug abuse in young adults. Am J Psychiatry 1988, 145(8):971-975

5. Gaidano G, Berta L, Rovero E, Valenzano C, Rosatti P: Dynamics of the binding capacity of plasma sex hormone binding globulin (SHBG) for testosterone and dihydrotestosterone during puberty. Clin Chim Acta 1980, 100(2):91-97 
6. Celotti F, Melcangi RC, Martini L: The 5 alpha-reductase in the brain: molecular aspects and relation to brain function. Front Neuroendocrinol 1992, 13(2):163-215

7. Kritzer MF: Long-term gonadectomy affects the density of tyrosine hydroxylase- but not dopamine-beta-hydroxylase-, choline acetyltransferase- or serotonin-immunoreactive axons in the medial prefrontal cortices of adultmale rats. Cereb Cortex 2003, 13(3):282-296.

8. Kritzer MF, Creutz LM: Region and sex differences in constituent dopamine neurons and immunoreactivity for intracellular estrogen and androgen receptors in mesocortical projections in rats. J Neurosci 2008, 28(38):9525-9535.

9. Perez SE, Chen EY, Mufson EJ: Distribution of estrogen receptor alpha and beta immunoreactive profiles in the postnatal rat brain. Brain Res Dev Brain Res 2003, 145(1):117-139.

10. Shughrue PJ, Lane MV, Merchenthaler I: Comparative distribution of estrogen receptor-alpha and beta mRNA in the rat central nervous system. J Comp Neurol 1997, 388(4):507-525.

11. Ravizza T, Veliskova J, Moshe SL: Testosterone regulates androgen and estrogen receptor immunoreactivity in rat substantia nigra pars reticulata. Neurosci Lett 2003, 338(1):57-61.

12. Poletti $A$, Martini L: Androgen-activating enzymes in the central nervous system. J Steroid Biochem Mol Biol 1999, 69(1-6):117-122.

13. MacLusky NJ, Walters MJ, Clark AS, Toran-Allerand CD: Aromatase in the cerebral cortex, hippocampus, and mid-brain: ontogeny and developmental implications. Mol Cell Neurosci 1994, 5(6):691-698.

14. Torres JM, Ortega E: Differential regulation of steroid 5alpha-reductase isozymes expression by androgens in the adult rat brain. FASEB J 2003, 17(11):1428-1433.

15. Krieger NR, Scott RG, Jurman ME: Testosterone 5 alpha-reductase in rat brain. J Neurochem 1983, 40(5):1460-1464

16. Beatty WW, Dodge AM, Traylor KL: Stereotyped behavior elicited by amphetamine in the rat: influences of the testes. Pharmacol Biochem Behav 1982, 16(4):565-568.

17. Walker QD, Cabassa J, Kaplan KA, Li ST, Haroon J, Spohr HA, Kuhn CM: Sex differences in cocaine-stimulated motor behavior: disparate effects of gonadectomy. Neuropsychopharmacology 2001, 25(1):118-130.

18. Dluzen DE, Ramirez VD: Effects of orchidectomy on nigro-striata dopaminergic function: behavioral and physiological evidence. J Neuroendocrinol 1989, 1(4):285-290.

19. de Souza Silva MA, Mattern C, Topic B, Buddenberg TE, Huston JP: Dopaminergic and serotonergic activity in neostriatum and nucleus accumbens enhanced by intranasal administration of testosterone. Eur Neuropsychopharmacol 2009, 19(1):53-63.

20. Thiblin I, Finn A, Ross SB, Stenfors C: Increased dopaminergic and 5-hydroxytryptaminergic activities in male rat brain following long-term treatment with anabolic androgenic steroids. Br J Pharmacol 1999, 126(6):1301-1306

21. Johnson ML, Day A, Ho CC, David Walker Q, Francis R, Kuhn CM: Androgen decreases dopamine neurone survival in rat midbrain. $J$ Neuroendocrinol 2010, 22(4):238-247.

22. Allan CM, Couse JF, Simanainen U, Spaliviero J, Jimenez M, Rodriguez K, Korach KS, Handelsman DJ: Estradiol induction of spermatogenesis is mediated via an estrogen receptor-alpha mechanism involving neuroendocrine activation of follicle-stimulating hormone secretion. Endocrinology 2010, 151(6):2800-2810.

23. Singh J, O'Neill C, Handelsman DJ: Induction of spermatogenesis by androgens in gonadotropin-deficient (hpg)mice. Endocrinology 1995 136(12):5311-5321.

24. Zirkin BR, Santulli R, Awoniyi CA, Ewing LL: Maintenance of advanced spermatogenic cells in the adult rat testis: quantitative relationship to testosterone concentration within the testis. Endocrinology 1989, 124(6):3043-3049.

25. Purves-Tyson TD, Arshi MS, Handelsman DJ, Cheng Y, Keast JR: Androgen and estrogen receptor-mediated mechanisms of testosterone action in male rat pelvic autonomic ganglia. Neuroscience 2007, 148(1):92-104.

26. Mooradian AD, Morley JE, Korenman SG: Biological actions of androgens. Endocr Rev 1987, 8(1):1-28.

27. Paxinos $G$, Watson $C$ : The rat brain in stereotaxic coordinates. 6th edition. Elsevier; 2007

28. Vandesompele J, De Preter K, Pattyn F, Poppe B, Van Roy N, De Paepe A Speleman F: Accurate normalization of real-time quantitative RT-PCR data by geometric averaging of multiple internal control genes. Genome Biol 2002, 3(7):1-12.

29. Harwood DT, Handelsman DJ: Development and validation of a sensitive liquid chromatography-tandem mass spectrometry assay to simultaneously measure androgens and estrogens in serum without derivatization. Clin Chim Acta 2009, 409(1-2):78-84.

30. McNamara KM, Harwood DT, Simanainen U, Walters KA, Jimenez M, Handelsman DJ: Measurement of sex steroids in murine blood and reproductive tissues by liquid chromatography-tandem mass spectrometry. J Steroid Biochem Mol Biol 2010, 121(3-5):611-618.

31. Horning S, Schanzer W, Donike M: Steroid profiling in human blood in: recent advances in doping analysis. volume 3. In Koln: Sport und Buch StrauB. Edited by Donike M, Geyer H, Gotzmann A, Mareck-Engelke U.; 1996:325-336

32. Weickert CS, Sheedy D, Rothmond DA, Dedova I, Fung S, Garrick T, Wong J, Harding AJ, Sivagnanansundaram S, Hunt C, et al: Selection of reference gene expression in a schizophrenia brain cohort. Aust N Z J Psychiatry 2010, 44(1):59-70.

33. Hafner H: Gender differences in schizophrenia. Psychoneuroendocrinology 2003, 28(Suppl 2):17-54.

34. Szymanski S, Lieberman JA, Alvir JM, Mayerhoff D, Loebel A, Geisler S, Chakos M, Koreen A, Jody D, Kane J, et al: Gender differences in onset of illness, treatment response, course, and biologic indexes in first-episode schizophrenic patients. Am J Psychiatry 1995, 152(5):698-703.

35. Salokangas RK: Gender and the use of neuroleptics in schizophrenia. Schizophr Res 2004, 66(1):41-49.

36. Beratis S, Gabriel J, Hoidas S: Age at onset in subtypes of schizophrenic disorders. Schizophr Bull 1994, 20(2):287-296.

37. Ravizza T, Galanopoulou AS, Veliskova J, Moshe SL: Sex differences in androgen and estrogen receptor expression in rat substantia nigra during development: an immunohistochemical study. Neuroscience 2002, 115(3):685-696

38. Kritzer MF: Selective colocalization of immunoreactivity for intracellular gonadal hormone receptors and tyrosine hydroxylase in the ventral tegmental area, substantia nigra, and retrorubral fields in the rat. J Comp Neurol 1997, 379(2):247-260.

39. Yamaguchi N, Yuri K: Changes in oestrogen receptor-beta mRNA expression in male rat brain with age. J Neuroendocrinol 2012, 24(2):310-318,

40. Creutz LM, Kritzer MF: Estrogen receptor-beta immunoreactivity in the midbrain of adult rats: regional, subregional, and cellular localization in the A10, A9, and A8 dopamine cell groups. J Comp Neurol 2002, 446 (3):288-300.

41. Zhao C, Dahlman-Wright K, Gustafsson JA: Estrogen signaling via estrogen receptor-beta. J Biol Chem 2010, 285(51):39575-39579.

42. Matthews J, Gustafsson JA: Estrogen signaling: a subtle balance between ER alpha and ER beta. Mol Interv 2003, 3(5):281-292.

43. Kuppers E, Krust A, Chambon P, Beyer C: Functional alterations of the nigrostriatal dopamine system in estrogen receptor-alpha knockout (ERKO) mice. Psychoneuroendocrinology 2008, 33(6):832-838.

44. Wang L, Andersson S, Warner M, Gustafsson JA: Morphological abnormalities in the brains of estrogen receptor beta knockout mice. Proc Natl Acad Sci U S A 2001, 98(5):2792-2796.

45. Beckstead MJ, Grandy DK, Wickman K, Williams JT: Vesicular dopamine release elicits an inhibitory postsynaptic current in midbrain dopamine neurons. Neuron 2004, 42(6):939-946.

46. Meyers B, D'Agostino A, Walker J, Kritzer MF: Gonadectomy and hormone replacement exert region- and enzyme isoform-specific effects on monoamine oxidase and catechol-O-methyltransferase activity in prefrontal cortex and neostriatum of adult male rats. Neuroscience 2010, 165(3):850-862.

47. Birgner C, Kindlundh-Hogberg AM, Oreland L, Alsio J, Lindblom J, Schioth HB, Bergstrom L: Reduced activity of monoamine oxidase in the rat brain following repeated nandrolone decanoate administration. Brain Res 2008, 1219:103-110.

48. Egan MF, Goldberg TE, Kolachana BS, Callicott JH, Mazzanti CM, Straub RE, Goldman D, Weinberger DR: Effect of COMT Val108/158met genotype on frontal lobe function and risk for schizophrenia. Proc Natl Acad Sci U S A 2001, 98(12):6917-6922.

49. Akil M, Kolachana BS, Rothmond DA, Hyde TM, Weinberger DR, Kleinman JE: Catechol-O-methyltransferase genotype and dopamine regulation in the human brain. J Neurosci 2003, 23(6):2008-2013. 
50. Roselli CE, Ellinwood WE, Resko JA: Regulation of brain aromatase activity in rats. Endocrinology 1984, 114(1):192-200.

51. Bortolato M, Frau R, Orru M, Bourov Y, Marrosu F, Mereu G, Devoto P, Gessa GL: Antipsychotic-like properties of 5-alpha-reductase inhibitors. Neuropsychopharmacology 2008, 33(13):3146-3156.

52. Paba S, Frau R, Godar SC, Devoto P, Marrosu F, Bortolato M: Steroid 5-Reductase as a Novel Therapeutic Target for Schizophrenia and Other Neuropsychiatric Disorders. Curr Pharm Des 2011, 17(2):151-167.

53. Swerdlow NR, Weber M, Qu Y, Light GA, Braff DL: Realistic expectations of prepulse inhibition in translational models for schizophrenia research. Psychopharmacology (Berl) 2008, 199(3):331-388.

54. Morris RW, Fung SJ, Rothmond DA, Richards B, Ward S, Noble PL, Woodward RA, Weickert CS, Winslow JT: The effect of gonadectomy on prepulse inhibition and fear-potentiated startle in adolescent rhesus macaques. Psychoneuroendocrinology 2010, 35(6):896-905.

55. Gogos A, van den Buuse M: Castration reduces the effect of serotonin-1 A receptor stimulation on prepulse inhibition in rats. Behav Neurosci 2003, 117(6):1407-1415.

56. van den Buuse M, Simpson ER, Jones ME: Prepulse inhibition of acoustic startle in aromatase knock-out mice: effects of age and gender. Genes Brain Behav 2003, 2(2):93-102

57. Weickert CS, Miranda-Angulo AL, Wong J, Perlman WR, Ward SE, Radhakrishna V, Straub RE, Weinberger DR, Kleinman JE: Variants in the estrogen receptor alpha gene and its mRNA contribute to risk for schizophrenia. Hum Mol Genet 2008, 17(15):2293-2309.

doi:10.1186/1471-2202-13-95

Cite this article as: Purves-Tyson et al:: Testosterone regulation of sex steroid-related mRNAs and dopamine-related mRNAs in adolescent male rat substantia nigra. BMC Neuroscience 2012 13:95.

\section{Submit your next manuscript to BioMed Central and take full advantage of:}

- Convenient online submission

- Thorough peer review

- No space constraints or color figure charges

- Immediate publication on acceptance

- Inclusion in PubMed, CAS, Scopus and Google Scholar

- Research which is freely available for redistribution 